\title{
Perceptions and knowledge of sexually transmitted diseases among rural people in India: Some ground realties
}

\author{
Nanjunda
}

Faculty Member, UGC-CSSEIP Research Centre, Mysore University, Karnataka, India.

\begin{abstract}
Sexually Transmitted Diseases (STDs) have become a serious public health issue among the rural people in India because of a unique health culture and health seeking behavior. Most rural people are suffering from different types of STDs because of cultural fabrics, poverty, illiteracy, ignorance and poor access to effective treatment. The World Health Organization has also warned that India could be the next nation with the highest number of unreported STD cases, resulting in devastating consequences. This current study, conducted in a rural part of the Hassan district of Karnataka, South India, examined the perceptions and knowledge regarding STDs among rural people. A focus group study conducted among selected purposive samples of both infected (with STD) and non-infected rural people. This study has found that STDs were more prevalent among people in the age group of 25-28 years (50.6\%) male respondents $(62.6 \%)$, people with a low level of literacy $(42.2 \%)$, professional truck drivers $(38.6 \%)$, people in the lower income groups $(64 \%)$, and unmarried people $(56 \%)$. This study also found vaginites and herpes are the most common types of STDs found among the respondents. The majority of the respondents were not aware about the onset and symptoms of the STDs. People were too shy to seek treatment even from the local healers. Effective public health policies and health promotion programs should be developed regarding the holistic and inclusive health development for the rural people with special references to STDs.
\end{abstract}

Keywords: STDs, Knowledge, Perception, Health Behavior, Rural people, India.

\section{Introduction}

Sexually transmitted diseases (STDs) are a major global cause of acute illness, infertility, long-term disability and dying of millions of men, women and infants. ${ }^{1}$ According to World Health organization, approximately 499 million new cases of curable STDs (syphilis, gonorrhoea, Chlamydia and Trichomoniasis) occur in 2008 throughout the world in adults aged 15-49 years. ${ }^{1}$ This estimate is $11 \%$ higher than the estimate for 2005 (498.9 million vs. 448.3 million). ${ }^{1}$ In the WHO South-East Asia Region, total incidence of selected curable STDs is 78.5 million: 7.2 million cases of C. trachomatis, 25.4 million cases of $\mathrm{N}$. gonorrhoeae, 3.0 million cases of syphilis and 42.9 million cases of T. vaginalis. ${ }^{1}$

STDs have become a serious public health issue in India. ${ }^{2}$ There are some social factors which play a vital role in increasing the risk of STDs including socio-economic status, occupation marital status, sexual disharmony etc. ${ }^{3}$ According to the National Behavioural Surveillance Survey, Karnataka is the state of having the fourth highest incidents of STDs in India. ${ }^{2}$ The current estimates national adult HIV prevalence in India is approximately $0.36 \%$, amounting to between 2 and 3.1 million people. ${ }^{2}$ If an average figure is taken, this comes to 2.5 million people living with HIV and AIDS, almost $50 \%$ of the previous estimate of 5.2 million. $^{3}$ Several STDs prevalence studies ${ }^{4-6,7}$ among female sex workers in India have shown widely varying rates across different parts of

\section{Practice Points}

- STDs have become a serious public health issue among the rural people in India because of a unique health culture and health seeking behavior.

- STDs were more prevalent among following categories of rural people: people with age group of $25-28$ years $(50.6 \%)$; male respondents $(62.6 \%)$; people with a low level of literacy $(42.2 \%)$; professional truck drivers $(38.6 \%)$; people in the lower income groups; $(64 \%)$ and unmarried people $(56 \%)$.

- It was also noted that vaginites and herpes are the most common types of STDs found among the rural people.

- The majority of the rural people were not aware about the onset and common symptoms of the STDs and they were too shy to seek treatment even from the local healers.

- There is an urgent need to implement cultural-sensitive and community-based sexual and reproductive health education programs focusing rural people, especially adolescents.

Correspondence: Dr. Nanjunda, Faculty Member, UGC-CSSEIP Research Centre, Mysore University, Karnataka, India. E-mail: ajdmeditor@yahoo.co.in. 
the country including Gonorrhea $0-19.1 \%$, Chlamydia $0.9-22.6 \%$, Syphilis $1.2-51 \%$ and Trichomoniasis 2$54.1 \%{ }^{8,9}$

It has been observed in India that change in the epidemiological trends particularly speedy increasing rate of STDs occurrence being noted in the high risk groups, specifically different drug users and commercial sex workers. ${ }^{5}$ Several studies ${ }^{8-12}$ found long distance truck drivers, middle class businessmen and construction workers are belongs to the high risk groups focusing rural region of the country. In India more than $70 \%$ of the populations reside in rural areas and increasing urban-rural migration is the major factor for the high prevalence of STDs in rural areas. ${ }^{12}$ High risk groups being in rural areas may spread HIV to the other general population as cautioned by various studies. ${ }^{7,13,14}$

Rural people are more vulnerable to the rapid spread of STDs. Urban and semi-urban area attracts more rural people, especially people who usually migrate searching for short-term and well-paid jobs. The DFID (Department for International Development, UK) report made clear that extensive travelling men may cause contact with multiple commercial sex workers ${ }^{15}$ and they spread STDs to their wives when they returned homes. ${ }^{16}$ Rural men, who are always mobile, may serve as a bridging population even for HIV not only between two genders, but also for two geographical locations. ${ }^{16}$

A number of studies ${ }^{9,14}$ have found that STDs are more commonly transmits from men to women in India. It is found that biologically women are more susceptible to STDs than men. ${ }^{17}$ One of the movements may be men have more decision-making power than women in relation to reproductive health in India. ${ }^{18}$

The important causes of increased incidence of STDs in rural areas include: unsafe sex, lack of awareness, illiteracy and strong social and ethnic factors, supernatural beliefs. ${ }^{5}$ Medical sociologists found that health care seeking behavior of the rural people also responsible for spreading STDs. ${ }^{16}$ Unprotected pre-marital and extra-marital relationship also causes more incidences of STDs/HIV in rural areas. ${ }^{19}$ Among the other key issues associated with STD are disagreeable sexual behavior, teenage pregnancy, sexual annoyance and growing rate of prostitution which may hamper the health of the society. ${ }^{20}$

It is also found that various types of STDs are causing high rate of morbidity and mortality among rural women and that they frequently present lacking any clinical symptoms. ${ }^{21}$ Experts have cautioned that because of lack of adequate knowledge about curable STDs the prevailing rate of HIV may increase among the rural folk. ${ }^{20}$

The current aim of this study is to examine the perceptions and knowledge about STDs and to measure the rate of prevalence of STD in rural parts of Hassan district of Karnataka, South India.

\section{Materials and methods}

The study was conducted in three selected villages of Hassan districts of south Karnataka state, India. The villages were selected based on the Reproductive and Child Health (RCH) Survey Report 2011. ${ }^{22}$ These villages have shown poor performance in the RCH Survey. This study has been conducted among 75 infected adolescents ( 25 adolescents from each village) and adolescents were selected using purposive sampling technique based on self-reporting and after verifying their medical records with the help of a local physician and assistance from the local health workers. A survey questionnaire was used to collect quantitative data and the same has analyzed using Minitab software. ${ }^{23}$ For some sociocultural reasons unmarried women and girls, pregnant and puerperal women were excluded from the study. The symptoms related to the various STDs were followed as recommended by the Government of India, Ministry of Health and Family Welfare guidelines. ${ }^{3}$ An interview schedule was also prepared using WHO interview schedules for diagnosis of STDs. ${ }^{1}$ Adolescents were interviewed in a private place. Data have verified for completeness and consistence.

\section{Results}

Table 1 shows the detailed background information of the respondents. This study has found that STD is more prevalent among the age group of 25-28 years $(50.6 \%)$. More than $29 \%$ of the age group of $18-19$ and $20 \%$ of the age group 20-24 years were suffering from STDs. It was also found that male members were more prone to STDs (62.6\%). Majority of STD cases found among illiterates $(42.2 \%)$ followed by the high school educated group $(25.3 \%)$. In case of occupation, $38.6 \%$ of professional truck drivers, $24 \%$ of migrant laborers, $12 \%$ skilled labors and 10.6\% unemployed adolescents were found to suffer from different types of STDs. This study also revealed that the low income group (64\%) is more prone to STDs followed by the middle income group $(30.6 \%)$. In case of marital status, unmarried and widow/widower are at more risk of being infected by STDs (56\% and $26.6 \%$ respectively).

The common prevalence of various cases of STDs among the respondents included gonorrhea (12\%) syphilis $(9 \%)$, herpes $(15 \%)$, and vaginitis $(18 \%)$. HIV infection was found to be less common among the studied groups (1\%) (Table 2). It is found that $29 \%$ of the respondents felt swelling genitals whereas $19 \%$ of them felt pain in the genital area, while $11 \%$ of them reported smelly discharges whereas $12 \%$ felt losing interest in sex were some of the vital symptoms of STDs (Table 3).

While asked about the main reasons of contracting STDs, the respondents mentioned the following: effects of sprits/breaching taboo (28\%), sex with strange people (14\%), eating/doing religions prohibited foods/deeds $(10 \%)$, unprotected sex $(11 \%)$ and sex with an infected person $(9 \%)$ (Table 3). For the treatment of STD problems, $29 \%$ of the respondents received treatment from the local traditional healers, $21 \%$ used home/self- 
Table 1: Background characteristics of the study population

\begin{tabular}{|c|c|}
\hline Variables & Respondents (\%) \\
\hline \multicolumn{2}{|l|}{ Age $(y r s)^{*}$} \\
\hline $18-19$ & $22(29.3 \%)$ \\
\hline $20-24$ & $15(20 \%)$ \\
\hline $25-28$ & $38(50.6 \%)$ \\
\hline \multicolumn{2}{|l|}{ Gender* } \\
\hline Male & $47(62.6 \%)$ \\
\hline Female & $28(37.3 \%)$ \\
\hline \multicolumn{2}{|l|}{ Educational level* } \\
\hline Primary education & $18(24 . \%)$ \\
\hline High school & $19(25.3 \%)$ \\
\hline College & $4(5.3 \%)$ \\
\hline Illiterates & $32(42.2 \%)$ \\
\hline Professional education & $2(2.6 \%)$ \\
\hline \multicolumn{2}{|l|}{ Occupational Status* } \\
\hline Migrant labors & $18(24 \%)$ \\
\hline Drivers & $29(38.6 \%)$ \\
\hline Skilled labor & $9(12 \%)$ \\
\hline Unemployed & $8(10.6 \%)$ \\
\hline Business & $7(9.3 \%)$ \\
\hline Garments & $4(5.3 \%)$ \\
\hline \multicolumn{2}{|l|}{ Income level (in Rs.)* } \\
\hline $3000-5000$ & $48(64 \%)$ \\
\hline $5000-10000$ & $23(30.6 \%)$ \\
\hline Above 10000 & $4(5.3 \%)$ \\
\hline \multicolumn{2}{|l|}{ Marital Status* } \\
\hline Married & $8(10.6 \%)$ \\
\hline Unmarried & $42(56 \%)$ \\
\hline Widow/widower & $20(26.6 \%)$ \\
\hline Others & $5(6.7 \%)$ \\
\hline \multicolumn{2}{|l|}{ Employment status* } \\
\hline Currently working & $33(44 \%)$ \\
\hline Not working & $42(56 \%)$ \\
\hline
\end{tabular}

*Values are significant $p<0.05$.

Table 2: Prevalence rate of STDs

\begin{tabular}{|l|c|}
\hline STDs & Respondents (\%) \\
\hline Gonorrhea & $12(16 \%)$ \\
\hline Syphilis & $9(12 \%)$ \\
\hline Herpes & $15(19 \%)$ \\
\hline Vaginitis & $18(24 \%)$ \\
\hline HIV & $1(1.3 \%)$ \\
\hline No such cases & $20(26.7 \%)$ \\
\hline
\end{tabular}

remedy, $26 \%$ got treatment from the faith healers and only $12 \%$ were treated by the modern medicine.

Regarding source of information about STD, $23 \%$ of the respondents received information from the local health workers, while $17 \%$ from the friends/relatives and $9 \%$ obtained information through various media. While asked about the non-treatment of STDs, the respondents mentioned the following reasons: shyness to seek treatment $(40 \%)$, cost $(20 \%)$, and time constraints (8\%). Regarding preventive measure (after being diagnosed
Table 3: Perceptions and knowledge of respondents

\begin{tabular}{|c|c|}
\hline Variables & Respondents (\%) \\
\hline \multicolumn{2}{|l|}{ Perceived symptoms of STDs* } \\
\hline Swelling in genitals & $29(38.7 \%)$ \\
\hline Pain in genital area & $19(25.3 \%$ \\
\hline Smelly discharges & $11(14.6 \%)$ \\
\hline Not interested in Sex & $12(16.0 \%)$ \\
\hline Other symptoms & $4(5.3 \%)$ \\
\hline \multicolumn{2}{|l|}{ Perceived Reasons for STDs* } \\
\hline Effects if sprits/ breach of taboo & $28(37.3 \%)$ \\
\hline Sex with unknown people & $14(18.6 \%)$ \\
\hline Religion prohibited foods/deeds & $10(13.3 \%)$ \\
\hline Sex with an infected person & $9(12 \%)$ \\
\hline Unprotected sex & $11(14.6 \%)$ \\
\hline Others & $3(4 \%)$ \\
\hline \multicolumn{2}{|l|}{ Sources of Treatment* } \\
\hline Traditional healer & $22(29.3 \%)$ \\
\hline Home/ self remedy & $21(28 \%)$ \\
\hline Faith healer & $20(26.6 \%)$ \\
\hline Western medicine & $12(16 \%)$ \\
\hline \multicolumn{2}{|l|}{ Source of Information about STDs* } \\
\hline Local health workers & $23(30.6 \%)$ \\
\hline Friends/ Relatives & $17(22.6 \%)$ \\
\hline Media & $9(12.1 \%)$ \\
\hline Others & $14(18.6 \%)$ \\
\hline \multicolumn{2}{|l|}{ Reasons for not taking treatment* } \\
\hline No time & $8(10.6 \%)$ \\
\hline Low priority/cost factor & $20(26.2 \%)$ \\
\hline Fear/shy & $30(40 \%)$ \\
\hline No idea & $8(10.2 \%)$ \\
\hline Under-treatment & $9(12 \%)$ \\
\hline \multicolumn{2}{|l|}{ Preventive Measure* } \\
\hline Nothing & $18(24.0 \%)$ \\
\hline Using Condoms & $21(28.0 \%)$ \\
\hline Never sex with infected person & $30(40 \%)$ \\
\hline Early treatment & $6(8.0 \%)$ \\
\hline
\end{tabular}

*Values are significant $p<0.05$.

with STDs), $18 \%$ of the respondents didn't take any preventive measures, $21 \%$ used condoms, and 30\% avoid sex with infected persons.

\section{Discussion}

This study has found that STD is more prevalent among the age group of $25-28$ years $(50.6 \%)$, male (vs. females) $(62.6 \%)$, illiterates $(42.2 \%)$, professional truck drivers $(38.6 \%)$, low income group $(64 \%)$ and unmarried people $(56 \%)$. It is generally reckoned that even though young people aged 18-23 years represent only $27 \%$ of having pre-material sexually experienced, they acquire more or less nearly half of all new STDs in various parts of the globe. ${ }^{16}$ It has been found that majority rural men visit cities in searching well-paid jobs and they were in contact with the commercial sex workers in the cities. In this way, men were infected with STDs and in turn infections were transmitted to their wives. Some studies have found that young people having multiple sexual partners, having unprotected sex, 
or involved in other high-risk sexual behaviors which are potential risk factors for acquiring various types of STDs. ${ }^{8}$ It is found that in majority cases rural community will not consider STDs is a serious health problem. ${ }^{15}$ They will get treatment only if STDs continues for a long time and severely hampering their daily life. Due to non-availability of lady physicians, rural women some time reluctant to visit local primary health care centres. ${ }^{19}$ Further it is found that poor access to healthcare, lack of awareness, the asymptomatic nature of certain STDs have also immensely contributed to increased prevalence of STDs among rural female adolescent. ${ }^{16}$ We also found that adolescents often discussed among the peer groups about STDs/HIV and the usage of contraceptives. Among the female adolescents, irregular menstrual cycle and urinary tract infection was the common topic of discussion with their friends. ${ }^{17}$

Moreover, it is found that majority primary health care centers in rural part do not have any preventive programs because of lack of human and financial resources. ${ }^{5}$ We found that STDs had implications on social and economical aspects of the patients and his/her family. ${ }^{16}$ Infected people usually seek treatment from local/faith healers cannot diagnose STDs and reluctant to visit health centers for social and financial reasons. ${ }^{9,17}$ Once they are diagnosed with STDs, this may hamper patients' personal image in the village and sometime friends and relative will avoid him/her or may have to face a kind of social isolation. ${ }^{4}$

The patients also reported that once they identified with STD they cannot attend any social functions in the village. Even today rural people in India are more interested to seek low-cost traditional treatment for STDs. ${ }^{13}$ The continuation of traditional health culture, unique health seeking behavior, poor health infrastructure, socio-cultural and religious barriers, and domination of local healers are some of the main barriers which prevent the STD patients in getting proper and timely treatment. ${ }^{8,12}$

The health culture and changing the reproductive behavior of the rural people in the studied village have been largely influenced due to contact with various external agencies including media and NGOs. Due to rapid economic growth, migration and expansion of cites, rural people are gradually porn to various STD diseases. Our study also found that rural people are less aware about the incidence of STDs and implications/ consequences of the diseases in their life. STDs has become a lifestyle-related disorder in rural areas. ${ }^{15}$ One of the worrying fact is that majority of the patients would not disclose their problems to anyone until it gets worse. The majority of them are not even considering STD is a very serious health issue and they are holding the perception of natural healing. It is probably due to the lower socio-economic conditions which may impact on their health seeking behavior. Moreover, the majority of the rural people have strong faith on the local healers for curing STDs. ${ }^{14}$

\section{Conclusion}

This study has found adolescents are more prone to various STD and majority of them are illiterates. It is also revealed that the majority of the infected respondents belong to the low-income group and most of them are unmarried adolescents. Moreover the long distance truck drivers are more prone to the STDs because of their nature of profession. This study found vaginites and herpes are the most common types of STD found among the respondents. Responds opined swelling in the genitals and pain are the most common symptoms of STD. Despise the availability of modern medical facilities, the incidence rate of STDs is increasing in rural areas, which may be due to socio-cultural and economic reasons.

There is an urgent need to implement cultural-sensitive and community-based sexual and reproductive health education programs focusing rural people, especially adolescents. Involvement of the village leaders and traditional healers is also essential for successful implementation of the programs. The traditional healers and local health workers should be properly trained in diagnosing and treatment of STDs.

\section{References}

1. WHO, Global incidence and prevalence of selected curable sexually transmitted infections2008. Geneva: World Health Organization, 2012.

2. National Aids Control Organisation (NACO). National Behavioural Surveillance Survey (BSS): General Population, 2006. New Delhi: NACO, 2006.

3. National AIDS Control Organisation. HIV data. New Delhi: NACO, 2007.

4. Shethwala ND, Mulla SA, Kosambiya JK, Desai VK. Sexually transmitted infections and reproductive tract infections in female sex workers. Ind J of Patho Microbi 2009; 52(2):198-9.

5. Diallo MO, Ghys PD, Vuylsteke B, EttiègneTraoré V, Gnaoré E, Soroh D, et al. Evaluation of simple diagnostic algorithms for neisseria gonorrhoeae and chlamydia trachomatis cervical infections in female sex workers in Abidjan, Cote d'Ivoire. Sex Transm Inf 1998;74 (suppl 1):S106-11.

6. Verma A, Shekhar S. Khobragade. Scale-up and coverage of Avahan: a large-scale HIVprevention programme among female sex workers and men who have sex with men in four Indian states. Sex Transm Inf 2010; 86 (suppl 1): i76-82.

7. Gangopadhyay DN, Chanda M, Sarkar K. Evaluation of sexually transmitted diseases/ human immunodeficiency virus intervention programs for sex workers in Calcutta. India $J$ Sexual Trans Dis 2005; 32(11): 680-4. 
8. Bhatnagar P, Kashyap V, Das DK. Clinico-epidemiological study of condylomatous lesions in inflammatory smears. J Obstet Gynaecol India 1991;41(4): 93-8.

9. Dhall K, Sarkar A, Sokhey C. Incidence of gonococcal infection and its clinicopathological correlation in patients attending gynaecological out-patient department. J Obstet Gynaecol India 1990;14(1):10-3.

10. Bhatia C, Jagdish D, Cleland J. Self-reported symptoms of gynaecological morbidity and their treatment in South India. Stud in Fam Plann 1995;6(4):203-16.

11. Chopra A, Mittal RR, Singh P, Sharma P. Patterns of sexually transmitted diseases at Patiala. Indian J Sex Transm Dis 1990;11(2) :43-5.

12. Bang RA, Bang AT, Baitule M, Chaudhary Y, Sarmukaddam S, Tale O. High prevalence of Gynaecological diseases in rural Indian women. Lancet 1989;46(9):14-4.

13. Kannan C, Athmaraman TN, Nayeem A, Sangeetha S, Sudha R. Ponsuganthi K. et al. Prevalence of reproductive tract infections among recently married women in Veerapandi Panchayat union of Salem district, Tamil Nadu. Indian J Community Med 2007; 13(2):144-65.

14. Mwambete KD, Mtaturu Z. Knowledge of sexually transmitted diseases among secondary school students in Dares Salaam, Tanzania. Afr Health Sci 2006;6(3):165-9.

15. Mitra, P. India at the crossroads: Battling the HIV/AIDS pandemic. Washington Quarterly 2004; 27(5):95-107.
16. Temin MJ, Okonofua FE, Omorodion FO, Elisha $\mathrm{P}$, Renne EP, Coplan $\mathrm{P}$, et al. Perceptions of sexual behavior and knowledge about sexually transmitted diseases among adolescents in Benin City Nigeria. Int Fam Plann Perspect 1999; 12 (6): 25-4.

17. Magadi AM. Curtis LS. Trends and determinants of contraceptive method choice in Kenya. Stud Fam Plann 2003; 34(3):149-59.

18. Nandan D. Improving Reproductive Health and Family Spacing in the state of Uttar Pradesh: Socio-clinical study of RTI/STD cases. New Delhi: CARE India, 1997.

19. Nandan D, Misra SK. Sharma A. Jain M. Estimation of prevalence of RTIs/STDs among women of reproductive age group in district Agra. Indian J Community Med 2002; 27(6):1013.

20. Pachauri S. Women's reproductive health: Research needs and priorities for developing countries. Paper presented at the South East Asia Regional Seminar on Social Dimensions of Health Care and Health Policy. NIHFW 1992; 23(7):3446.

21. Pelto PJ, Joshi A, Verma R. Development of sexuality and sexual behaviour among Indian Males: Implications for the Reproductive Health programme. Popul Coun Report 2000; 12(7) :1619.

22. Reproductive and Child Health ( $\mathrm{RCH})$ Survey Report. Bangalore: Govt. of Karnataka, 2011.

23. Prakesh H. Statistics for Social Science Research. Mysore: Spring leaf Publications, 2012. 